\title{
Phytorestoration of DDT-contaminated soil by pumpkin
}

\author{
Siwen Li \& Peng Li \& Lina Sun \& Dongmei Zheng \\ Key Laboratory of Regional Environment and Eco-Remediation, Ministry of Education, Shenyang \\ University, Shenyang 110044, China
}

Keywords: Pumpkin; DDT; Phytoremediation.

\begin{abstract}
To choose cucurbitaceous plant pumpkin as the selected plant and the paper initially discussed on the repair effects of DDT-contaminated soil by pumpkin under a variety of measures. Results showed that the content of DDT in soil reduce significantly after the same repair period. The experimental group which have the most obvious repair effect has two kinds of bacteria for control measures. The second one added compound fertilizer as measures.
\end{abstract}

\section{Introduction}

Soil is one of the most important natural resources which collected about $90 \%$ of the pollutants in environment. Therefore there are many different kinds of soil pollutants, the soil pollution problem has become increasingly seriously.

Although as early as in 70-80s of the $20^{\text {th }}$ century, most countries in the world had to stop using the Organ chlorine pesticide DDT, but its effects on ecological environment is still there. DDT is the first batch of listed in the 'high pollution, high environmental risk' products list of the pollution list of the pollutants in China. The world health organization reports that china's adult male HCH intake is 15 times more than Japan's and 84 times more than American's. DDT intake is 16 times more than Australia's and 24 times more than Japan's and American's. People's health risk is huge in our country, even the content of DDT and other pesticides in human breast milk is still significantly higher than that of developed countries and relevant international organizations of standards. As a result, the fixing problem of DDT in soil was imminent.

In the repair of DDT-contaminated soil, the principle of phytoremediation plant secretion to degradation of organic pollutants concentration bio surfactant. Choosing pumpkin as the tested plants for phytoremediation, pumpkin as the annual cucurbitaceous plants, it can be resistant to DDT pollution, easy dry biomass, root developed, field management, to adapt to the characteristics of northern climate, the economic value.At the same time also added several control measures, such as compound fertilizer and two types of plant growth promoting rhizobacteria.

Wang and others show that fertilizer is commonly used to improve the quality of crop yield and soil as an agronomic measure. In the repair process, the use of fertilizer on the degradation of organic pollutants in soil also has the certain influence.

Staphylococcus pasteuri and Agrobacterium tumefactions produce organic acid, amino acid, and polysaccharide, hormones which can be advantageous to absorb and make use of the material. As the important function in the microbial fertilizer bacterium, Staphylococcus pasteuri and Agrobacterium tumefactions can increase the crop yield and the quality.

This article chooses pumpkins as the selected plant and repairs the DDT pollution soil by different control measures. The results may show the effect of pumpkin repair DDT pollution soil, and whether a threat to human health.

\section{Materials and methods}

\subsection{Materials}

The soil in Shenyang city Xinmin city Dalama Aoduoniu village vegetable base, cucurbitaceous plant pumpkin, fertilizer, Staphylococcus pasteuri and Agrobacterium tumefactions, n-hexane, acetone, chromatographically pure n-hexane and other organic solvents. 


\subsection{Methods}

Several experimental groups that deal with soil are designed: the control check group, the plant+ fertilizer group, the plant + Staphylococcus pasteuri group, the plant + Agrobacterium tumefactions' group, the plant + Staphylococcus pasteuri+ Agrobacterium tumefactions' group. All of the groups are planted through the same cycle. To test the variation of DDT in soil samples before and after the experiment, accelerated solvent extraction, rotary evaporation, solid phase extraction method are elected.

\section{Results and discussion}

As the selected plant, pumpkin showed stronger resistance to DDT and had obvious effect to repair the pollution soil. The combined action of Staphylococcus pasteuri and Agrobacterium tumefactions' play a significant role in promoting the repair. Fertilizer was the second one to promote the repair. Staphylococcus pasteuri or Agrobacterium tumefactions' almost made nothing in promoting the repair.

\section{Acknowledgement}

The authors are grateful to the support of National Key Basic Research Program of China (2014 CB441106), Shenyang city science and technology project (F14-133-9-00), the general project of Liaoning province department of education (L2013454) and Competitive selection project of Shenyang scientific undertaking.

\section{References}

[1] Agamuthu P.Phytoremediation of Soil Contaminated with Used Lubricating Oil using Jatropha Curcas[J].Journal of Hazardous Materials,2010, 179: 891-894.

[2] Chithrashree A C.Plant Growth-promoting Rhizobacteria Mediate Induced Systemic Resistance in Rice against Bacterial Leaf Blight Caused by Xan-thomonas Oryzae pv, Oryzae.Biol, Control, 2011, 59:114-122.

[3] Fernandez M D.Terrestrial Microcosms in a Feasibility Study on the Remediation of Diesel-contaminated Soils [J].Ecotoxicology and Environmental Safety,2011,74: 2133-2140.

[4] HUANG Huan-fang. Distribution Characteristics and Risk Assessment of Organochlorine Pesticides in Soil from Jiufeng Mountain Range in Fujian,China[J].Environmental Science, Vol. 35, No.7, Jul,2014.

[5] LUO Yongming. Current Research and Development in Soil Remediation [J].Progress In Chemistry,Vol.2, No.2 3r,Mar,2009r.

[6] Su Jiaxin.Effects of Rhizospheric Microbes and Soil Enzymes on the Biodegradation of PCB in the Soil within Intercropping Systems[J].Journal of Agro-Environment Science, 2010, 29(11):2114-2120.

[7] Sheng X F.Promotion of Growth and Cu Accumulation of Bio-energy Crop (Zea mays) by Bacteria: Implications for energy plant biomass production and phytoremediation.J Environ Manag, 2012, 103:58-64.

[8] Shanmugam V.Biocontrol of Vascular Wilt and Corm Rot of Gladiolus Caused by Fusarium Oxysporumf sp Gladioli using Plant Growth Promoting Rhizobacterial Mixture. Crop Protect, 2011, 30:807-813.

[9] Teng Ying.Combined Remediation Effects of Arbuscular Mycorrhizal Fungi-LegumesRhizobium Symbiosis on PCBs Contaminated Soils[J]. Environmental Science, 2008, 10.

[10]TU Chen.Phytoremediation of Polychorinated Biphenyls Contaminated Soil by LeguminosaeGramineae Intercropping:A Field Trial[J]. Environmental Science, Vol.31, No.12, Dec, 2010.

[11]Xu SY.Enhanced Dissipation of Phenanthrene and Pyrene in Spiked Soils by Combined Plants Cultivation.Science of the Total Environment 363(1-3):206-215. 
[12]XIA Yan .Research Progress of Mechanism of Action of Plant Growth Promoting Rhizobacteria[J].Agricultural Science \& Technology, 2014, 15(1):87-90,110.

[13]Yuttavanichakul W.Improvement of Peanut Rhizobial Inoculant by Incorporation of Plant Growth Promoting Rhizobacteria(PGPR) as Biocontrol against the Seed Borne Fungus Aspergillus Niger.Biol Control,2012,63:87-97.

[14]Zhuo Sheng.Effects of Rhizo-remediation Polychlorinated Biphenyl Contaminated Soil Under Intercropping System[J].Journal of Agro-Environment Science, 2010, 29(1):73-77.

[15]Zhu Zhiqiang.Plant-microbe Remediation of Cd-DDT Co-contaminated Soils and Its Mechanisms [D]. Hangzhou: Zhejiang University, 2012. 